\title{
Prospective Survey of Antibiotic Utilization in Pediatric Hospitalized Patients to Identify Targets for Improvement of Prescription
}

\author{
M. Potocki, J. Goette, T. D. Szucs, D. Nadal
}

\begin{abstract}
Background: The rise in the use of antibiotics has resulted in increasing health care costs and the emergence of resistant bacteria. Little is known about the general misuse of antibiotics in hospitalized children. We evaluated the utilization of antibiotics in a pediatric teaching hospital aiming to identify targets for improvement of prescription. Patients and Methods: Clinical, radiological, laboratory and treatment data of patients hospitalized in a pediatric medical and a pediatric surgery ward were prospectively collected during a 6-week period. A subsequent review of the collected data by a pediatric infectious diseases specialist, taking into consideration existing in-house treatment guidelines, was carried out.

Results: A total of 125 (36\%) of 349 patients was prescribed 246 antibiotics. The median length of hospital stay for children prescribed antibiotics was 5 days (range, 2-30 days) and for those not prescribed 3 days (1-32 days; $\mathrm{p}<0.001)$. Of 154 patients in the medical ward, $64(42 \%)$ received antibiotics, compared to $61(31 \%)$ of 195 patients in the surgical ward $(p<0.05)$. Empirical prescriptions were more frequent than prophylactic ones, which were more frequent than therapeutic prescriptions (136 [55\%] vs 94 $[38 \%]$ vs $16[7 \%] ; p<0.001)$. Overall, $85 \%$ of the prescriptions were considered justified. The rates of inappropriate prescriptions were similar in the medical and surgical ward, and higher for therapeutic (19\%) or prophylactic treatment (18\%) than for empirical treatment $(12 \%)$. Higher inappropriate prescription rates were noted for macrolides than for co-trimoxazole and $\beta$-lactams ( $50 \%$ vs $18 \%$ and $15 \%$, respectively; $p<0.05$ ).

Conclusion: Efforts need to be undertaken towards continuous education of medical staff on judicious antibiotic use, as well as ensuring compliance with existing guidelines. Improvement in the availability of rapid diagnostic methods to discern viral from bacterial infections may help reduce the numbers of empiric therapies in favor of pathogen-targeted therapeutic treatments.
\end{abstract}

Infection 2003; 31: 398-403

DOI 10.1007/s15010-003-4130-1

\section{Introduction}

In the last two decades a relentless rise in the use of antibiotics has resulted in costs of more than 7 billion dollars annually in the United States with up to 4 billion used for treatment of nosocomial infections due to antibiotic-resistant bacteria [1]. It has been estimated that antibiotic expenditures can account for up to $50 \%$ of a hospital's total drug budget [2]. In children, antibiotics are among the most commonly prescribed drugs [3]. Approximately $35 \%$ of admitted infants and children receive antibiotics [4-9]. Widespread misuse of antimicrobial agents has been reported for adults in the last few years, but only little is known about pediatric patients. Overall, almost half of all antibiotic prescriptions have been found to be inappropriate [3,4,10-12].

The reasons for concern about excessive use of antibiotics are the increasing burden of resistant bacteria, adverse reactions to these drugs and excessive costs [13]. Preventing the emergence of resistant bacteria and their dissemination will reduce these adverse effects and attendant costs. Appropriate antimicrobial stewardship that includes optimal selection, dose and duration of treatment as well as control of antibiotic use will prevent or slow the emergence of resistant bacteria.

For the prevention of antimicrobial resistance in hospitals new strategies have been developed by a consensus group of the Society for Health Care Epidemiology of America and the Infectious Diseases Society of America (IDSA) [14]. Several strategies and guidelines have been used to diminish injudicious antimicrobial use. Multidisciplinary antimicrobial management programs (AMPs) were

\footnotetext{
D. Nadal (corresponding author), M. Potocki

Division of Infectious Diseases, University Children's Hospital of Zurich, Steinwiesstrasse 75, CH-8032 Zurich, Switzerland; Phone: (+41/1)-2667562, Fax: -7157, e-mail: david.nadal@kispi.unizh.ch J. Goette

Division of Pharmacy, University Children's Hospital of Zurich, Zurich, Switzerland

T. D. Szucs

Division of Hospital Economics, University Hospital of Zurich, Zurich, Switzerland
} 


\begin{tabular}{|c|c|}
\hline Category & Criteria \\
\hline I & $\begin{array}{l}\text { Correct indication; appropriate choice of antibi- } \\
\text { otics, dosing and duration of treatment }\end{array}$ \\
\hline II & $\begin{array}{l}\text { Correct indication; inappropriate choice of an- } \\
\text { tibiotics, and/or dosing and duration of treat- } \\
\text { ment }\end{array}$ \\
\hline III & No indication for use of antibiotics \\
\hline
\end{tabular}

introduced in hospitals, and many studies have described the clinical and economic impact of such programs $[1,2$, 15-24]. While in many studies evaluation of interventions has focused on the reduction in the volume and costs of antimicrobial agents, few have documented the effect of such interventions on the appropriateness or accuracy of antibiotic use.

There is, to the best of our knowledge, only one study that describes the impact of an AMP on expenditures, antimicrobial resistance rates, and clinical outcomes in a pediatric institution [25]. Physicians caring for children deal with an age-group that is not only prone to viral infections not requiring antimicrobial therapy, but may also be especially vulnerable to non-immediately treated and rapidly progressing bacterial infections [4].

The first step for establishing an AMP in a hospital is to gather knowledge about the local budget for and patterns of antimicrobial usage [1]. In the present study the utilization of antibiotics was examined to identify targets for strategies to improve the use of antibiotics in pediatric hospitals and to point out the specific problems of AMPs for hospitalized children.

\section{Patients and Methods Patients}

This prospective study was carried out at the University Children's Hospital of Zurich, Switzerland, a tertiary care center that is also the largest secondary care center in the area, providing extensive primary care through the walk-in emergency department as well. Over a 6-week consecutive period (February 11 to March 24, 2001) all hospitalized patients in one medical and one surgical ward were checked for antibiotic prescriptions. Both wards were randomly chosen among the four medical and three surgery wards providing medium care in the whole spectrum of pediatrics and pediatric surgery, respectively, and caring for children from the 1 st year to 16 years of age.

\section{Data Gathering}

Data were collected on daily visits to the two selected services. Medical and nursing records served to gather demographic characteristics (e.g., age, gender, weight, date of admission and discharge, provisional and final diagnosis, comorbidities) and the prescription of antibiotics for each patient including dose, frequency, duration, route of administration and prescription time. Moreover, the clinical focus and relevant microbiological laboratory results, if present, were recorded and direct (statement in the chart) or indirect information (clinical, radiological, microbiological findings) on the indication for antibiotic prescription was obtained. If the indication was not stated in the patient's chart, antibiotic use was defined as therapeutic when prescribed for bacterial infection with presence of clinical or radiological evidence (e.g., abscess, infiltrate on chest X-ray, osteolytic lesion with systemic signs of infections) and microbiological documentation of bacterial infection. It was defined as empirical when prescribed in the presence of clinical or radiological features suggestive of infection, but without microbiological proof of bacterial infection; or as prophylactic when in-

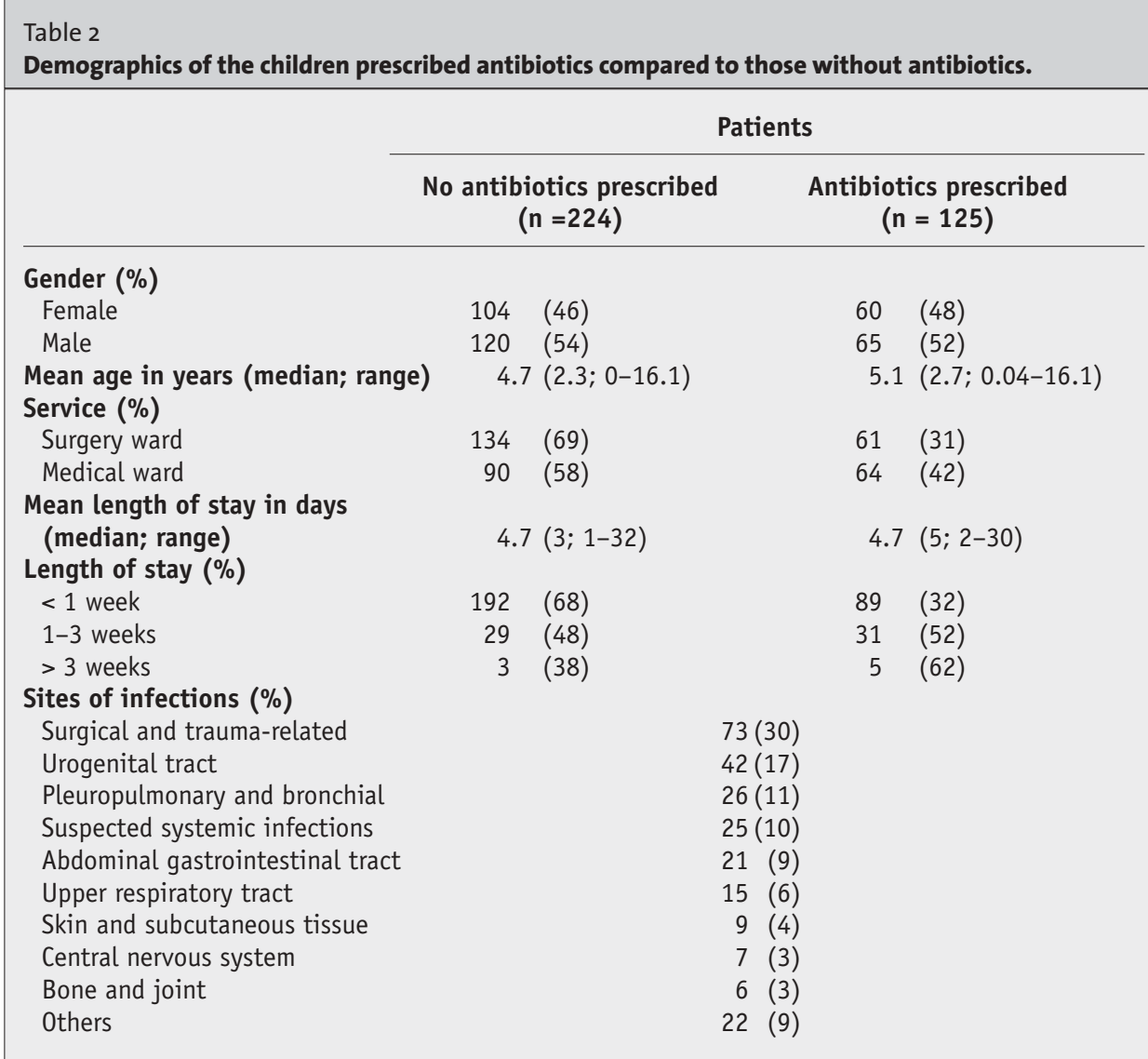


tended to prevent infections, e.g. perioperatively or in certain immunocompromised patients.

\section{Data Interpretation}

The suitability of each antibiotic prescription was reviewed by an infectious diseases specialist unaware of the patients since not on duty and blinded to the names of the patients when judging the data available at the time of prescription. The specialist classified them into categories I-III according to set criteria (Table 1). Category I was defined as appropriate use of antibiotics and categories II and III as inappropriate.

The physicians were free in their choice of antimicrobial treatment and had the possibility to consult the infectious diseases specialist at any time. Inhouse guidelines for perioperative antibiotic prophylaxis and for the treatment of the most common and for severe bacterial infections existed in both wards and could be downloaded from the intranet. These guidelines, last updated in December 2000, were based on the Red Book 2000 of the American Academy of Pediatrics [26], a textbook of pediatric infectious diseases [27], and a book on pediatric antimicrobial therapy [28]. Updates of the guidelines are mailed with a covering letter in envelopes personally addressing each member of the medical staff. To minimize a potential influence on the prescription patterns, neither the physicians nor the nursing staff was informed about the aim of the study.

\section{Statistics}

The data were analyzed with the aid of a computerized database (FilemakerPro5, Filemaker, Inc.) and an epidemiological statistical package (SPSS 10.0, SPSS, Inc.). Differences between groups were tested by the $\chi^{2}$-test and unpaired t-tests. A p-value less than 0.05 was considered as statistically significant.

\section{Results}

\section{Antibiotic Prescriptions}

Table 2 gives the demographics of the patients hospitalized in the two selected wards during the 6 weeks of study and the proportion of patients prescribed antibiotic regimens. A total of 349 patients was admitted to the selected wards during the study period. 125 of these patients (36\%) re-

\begin{tabular}{|c|c|c|c|c|c|c|}
\hline \multirow[b]{2}{*}{ Indication for prescription } & \multicolumn{2}{|c|}{ Medical ward } & \multicolumn{2}{|c|}{ Surgical ward } & \multicolumn{2}{|c|}{ Total } \\
\hline & No. & $\%$ & No. & $\%$ & No. & $\%$ \\
\hline Empiric & 67 & 59 & 69 & 52 & 136 & 55 \\
\hline Appropriate & 58 & 87 & 62 & 90 & 120 & 88 \\
\hline Therapeutic & 8 & 7 & 8 & 6 & 16 & 7 \\
\hline Appropriate & 7 & 88 & 6 & 75 & 13 & 81 \\
\hline Prophylactic & 38 & 34 & 56 & 42 & 94 & 38 \\
\hline Appropriate & 32 & 84 & 45 & 80 & 77 & 82 \\
\hline Total prescriptions & 113 & 46 & 133 & 54 & 246 & 100 \\
\hline Appropriate & 97 & 86 & 113 & 85 & 210 & 85 \\
\hline
\end{tabular}

ceived antibiotics during their hospitalization. The mean length of hospital stay for children receiving antibiotics was 7 days (median, 5 days; range, 2-30 days) versus 4.7 days (median, 3 days; range, 1-32 days) for patients not receiving any antibiotics $(\mathrm{p}<0.001)$. With increasing length of stay the proportion of patients receiving antibiotics augmented, ranging from $32 \%$ of those staying less than 1 week to $62 \%$ of those staying longer than 3 weeks $(p<0.01)$. The mean exposure time to antibiotics was 4.8 days (range, 1-29 days) for all children; for children younger than 1 year it was 4.4 days and for children over 10 years of age it increased to 8.0 days $(\mathrm{p}<0.01)$. Patients in the surgery ward were exposed longer to antibiotics than patients in the medical ward (mean 6.3 days vs 3.4 days; $\mathrm{p}<0.001$ ).

Of a total of 246 prescribed antibiotics 136 (55\%) were initiated empirically, 94 (38\%) were intended for prophylactic use and $16(7 \%)$ given therapeutically $(\mathrm{p}<0.001$ for all three types of prescription). The routes of administration were $67 \%$ intravenous, $31 \%$ oral and $2 \%$ intramuscular. During hospitalization $75 \%, 21 \%$ and $4 \%$ of all children received one, two or three antibiotics, respectively. Of 154 patients admitted to the medical ward, $64(42 \%)$ received antibiotics versus $61(31 \%)$ of 195 patients admitted to the surgery ward $(\mathrm{p}<0.05)$. Table 3 shows that the relative distribution of therapeutic, empirical and prophylactic prescriptions in the medical and the surgical ward were similar. Also, the frequencies of the routes of administration were statistically not significantly different between the wards (data not shown).

\section{Justification and Appropriateness of Antibiotic Prescriptions}

Overall, prescription of antibiotics was considered justified in $85 \%$ of patients. The 191 prescriptions encompassed 246 antibiotic courses, of which 210 (85\%) were judged appropriate (category I) and $36(15 \%)$ inappropriate (categories II and III). Of these, $10 \%$ fell into category II as inappropriate and $5 \%$ of all prescribed antibiotics were given without obvious or chart-specific recorded indication (category III). Table 3 shows that higher rates of inappropriate prescription were noted for therapeutic $(19 \%)$ and for prophylactic treatment (18\%) than for empirical treatment $(12 \% ; \mathrm{p}>0.05)$. The rates of inappropriate antibiotic prescriptions in the medical and surgical wards were similar.

\section{Adequacy of the Group of Antibiotics Prescribed}

Table 4 lists the groups of antibiotics prescribed and the adequacy of prescrip- 
tion with respect to the intended use. $\beta$-lactams and co-trimoxazole were the most commonly prescribed antibiotics and accounted for $67 \%$ and $13 \%$ of all prescribed antibiotics, respectively. The $\beta$-lactams included amoxicillin plus clavulanic acid (35\%), amoxicillin (30\%), second- and third-generation cephalosporins (18\% and 12\%, respectively), flucloxacillin (3\%) and meropenem (3\%). Other compounds such as metronidazole, quinolones, glycopeptides and antituberculous drugs accounted for $12 \%$ of all prescribed antibiotics.

For empirical treatment amoxicillin plus clavulanic acid was most often prescribed, for prophylaxis, amoxicillin and second-generation cephalosporins, and for therapeutical treatment, second- and third-generation cephalosporins and co-trimoxazole. Overall, the highest rate of inappropriate prescription purpose was noted for macrolides with $50 \%$, followed by co-trimoxazole and $\beta$-lactams with $18 \%$ and $15 \%$, respectively $(\mathrm{p}<0.05)$. Regarding empirical treatment, $50 \%$ of the macrolide prescriptions, $20 \%$ of co-trimoxazole prescriptions and $10 \%$ of $\beta$-lactam prescriptions were inappropriate $(\mathrm{p}<0.05)$. With respect to prophylactic treatment $\beta$-lactams were the group of antibiotics with the highest rate of inappropriate prescriptions (28\%) followed by co-trimoxazole $(15 \%)$; for therapeutic treatment it was co-trimoxazole with $33.3 \%$ and $\beta$-lactams with $22.2 \%$ $(\mathrm{p}>0.05)$.

\section{Discussion}

This study recording the prescription patterns for antibiotics in a university children's hospital estimated that almost one in five therapeutic or prophylactic prescriptions and one in seven empirical prescriptions were inappropriate, whereby macrolides were more often inappropriately prescribed than antimicrobials from other classes.

This prospective study was conducted during a 6-week period in one medical and one surgical ward. Both were randomly chosen from among a group of wards which performed and were staffed similarly. Therefore the results from each of both wards can be regarded as representative for the other wards of the respective discipline. So far, five studies investigating and evaluating antibiotic use for pediatric patients in the hospital setting have been published. Four studies were prospective $[4,10-12]$ and one study retrospective in nature [3]. In the prospective studies, the observation periods lasted 3 months, 6 months (3 days per week) and 12 months (1 week per month) and the numbers of antimicrobial prescriptions recorded and assessed were 312,318,325 and 428. Thus, in comparison with these studies' shorter period of observation, the somewhat lower number of 246 prescriptions assessed in our study may be regarded as a limitation. However, the period of observation was chosen in the cold season when, for example, viral respiratory tract infections are more frequent, the rate of community-acquired infections requiring hospitalization is more frequent and the prescription of antibiotics more likely. Therefore, the results from our study may nevertheless serve to create a baseline from which a policy for improvement in antibiotic usage could be devised, also in regard to different pediatric patient populations.

Various methods have been used to evaluate the quality of antibiotic prescribing. Schollenberg and Albritton [3] and Naqvi et al. [4] employed evaluating criteria similar to ours, based on the system of Kunin et al. [29], but Naqvi et al. [4] disregarded the duration of the planned treatment. The main criteria were appropriate indication for use of antimicrobial agents, appropriate drug choice and appropriate duration of the treatment. Swindell et al. [30] and Moss et al. [31] used two main assessors to judge the prescriptions, whereas we had one infectious diseases specialist as had Schollenberg and Albritton [3] and Mora et al. [12] who assessed all the prescriptions "in the light of currently accepted practice."

The proportion of hospitalized pediatric patients prescribed antibiotics in our study was $36 \%$, being higher in medical than in surgical patients $(42 \%$ vs $31 \%$; $<<0.05)$. This is within the range of $22-70 \%$ previously reported from other pediatric units [3-5, 12,32-34]. It is remarkable that studies in North America [3-5] and Central Europe $[32,33]$ have shown fewer patients exposed to antibiotics than countries in South America [12] or Eastern Europe [34]. Also, the rates for patients in intensive care units [32, 33] were higher than for patients in medium care units [3, $4,12]$. No relation to season was stated and no comparison

\begin{tabular}{|c|c|c|c|c|c|c|}
\hline \multirow{3}{*}{$\begin{array}{l}\text { Compounds } \\
\beta \text {-lactams } \\
n=164(67 \%)\end{array}$} & \multirow{3}{*}{$\begin{array}{l}\begin{array}{l}\text { Adequacy of } \\
\text { prescription }\end{array} \\
\begin{array}{l}\text { Appropriate } \\
\text { Inappropriate }\end{array}\end{array}$} & \multirow{2}{*}{$\begin{array}{c}\begin{array}{c}\text { Empiric } \\
\text { n (\%) }\end{array} \\
82(90)\end{array}$} & \multirow{2}{*}{$\begin{array}{c}\text { Therapeutic } \\
\text { n (\%) }\end{array}$} & $\begin{array}{c}\text { Prophylactic } \\
\text { n (\%) }\end{array}$ & \multicolumn{2}{|c|}{$\begin{array}{l}\text { Total } \\
\text { n (\%) }\end{array}$} \\
\hline & & & & $50 \quad(72)$ & 139 & (85) \\
\hline & & $9(10)$ & $2(22)$ & $14 \quad(28)$ & 25 & (15) \\
\hline Co-trimoxazole & Appropriate & $8(80)$ & $2(67)$ & 17 (85) & 27 & (82) \\
\hline$n=33(13 \%)$ & Inappropriate & $2(20)$ & $1(33)$ & 3 (15) & 6 & (18) \\
\hline Aminoglycosides & Appropriate & $13(100)$ & $0 \quad(0)$ & $1(100)$ & 14 & (100) \\
\hline $\mathrm{n}=14(6 \%)$ & Inappropriate & $0 \quad(0)$ & $(0)$ & $\begin{array}{ll}0 & (0)\end{array}$ & 0 & (0) \\
\hline Macrolides & Appropriate & $3(50)$ & $(0)$ & $(0)$ & 3 & (50) \\
\hline$n=6(2 \%)$ & Inappropriate & $3(50)$ & $0 \quad(0)$ & $0 \quad(0)$ & 3 & (50) \\
\hline Others & Appropriate & $14(88)$ & $4(100)$ & $9(100)$ & 27 & (93) \\
\hline$n=29(12 \%)$ & Inappropriate & 2 (12) & $0 \quad(0)$ & $0 \quad(0)$ & 2 & $(7)$ \\
\hline
\end{tabular}


with studies for adult patients was done, except by one study which also showed frequent errors of all types in adult hospitals [3].

Prescription of antibiotics in this investigation was judged to be inappropriate in $15 \%$ of cases. So far, only three studies have attempted to quantify the percentage of inadequate antibiotic treatment regimens for pediatric patients and their results were $36 \%, 40 \%$ and $45 \%[3,4,10]$. Naqvi et al. [4] found for medical patients a $21 \%$ rate of inappropriate prescriptions, a rate similar to our finding, and Schollenberg and Albritton 30\% [3]. The rates for surgical patients were $63 \%$ and $66 \%$, respectively $[3,4]$. Both institutions used guidelines for surgical prophylaxis but only one institution [4] also used guidelines for medical prophylaxis. Further, both studies had an infectious disease specialist, as in our study, who reviewed each case by published criteria which were followed for the assessment. Principi et al. [10] focused on antibiotic prescriptions for otitis, pneumonia, and pharyngotonsillitis, used guidelines for judgement and found that $40 \%$ were inappropriate prescriptions. It is not clear whether an infectious disease specialist was involved in the assessment of this study. The results from our institution are rather favorable compared to those of other institutions, and may mirror an increased awareness of the physicians that judicious use of antibiotics is important. They may also be a consequence of the fact that the infectious diseases service issues inhouse guidelines for both medicine and surgery departments and supports both departments with recommendations.

In our study period around half of all antibiotics were started on an empirical basis, i.e. without clear-cut clinical or without microbiological documentation of a bacterial infection. Van Houten et al. [33] reported a similar proportion of empirical antibiotic therapy with $58 \%$. Studies in adult patients also showed high rates of empirical therapy: $57 \%$ and $71 \%[31,35]$. The appropriateness of empiric therapy in our study was judged to be correct in $88 \%$ of cases, which is higher but statistically not significantly different from prophylactic and therapeutic therapy with rates of $82 \%$ and $81 \%$, respectively. This relatively higher proportion of appropriateness for empiric therapy may be explained by the fact that a broader choice of antibiotics can be regarded as justified when the pathogen is unknown. The fact that almost one fifth of the prescriptions for prophylactic therapy and therapeutic therapy was inappropriate is remarkable in view of existing inhospital guidelines for both prophylaxis and treatment of clinically or microbiologically documented bacterial infection. This suggests that the prescribers were insufficiently aware of existing guidelines, had limited knowledge of the most likely causative infectious agents or were non-compliant with the guidelines. On the other hand this observation illustrates that assessment of local prescribing patterns may serve as an important tool to reveal weaknesses within the hospital setting and can in turn pave the way for targeted and tailored problem solving. In our case, this would point to a need to in- tensify teaching on the use of antimicrobial drugs and information on existing guidelines. We decided to provide structured comprehensive teaching on the most likely causative microorganisms for the most common infectious diseases in pediatrics and on antimicrobials for medical staff twice a year. At every possible occasion in daily routine, we also intend to remind the medical staff of the need to adhere to existing guidelines.

The macrolides were the group of antimicrobial agents with the highest rate of inappropriate use in this study with $50 \%$, followed by co-trimoxazole and $\beta$-lactams with $18 \%$ and $15 \%$, respectively. Only Schollenberg and Albritton [3] investigated the appropriateness of the selected antimicrobial agents, finding more than $75 \%$ of the macrolides inappropriate, followed by tetracyclines with a $50 \%$ rate. In our study the number of macrolide prescriptions was relatively low compared to other antibiotics. Furthermore, the main reason for macrolide prescription in this investigation was respiratory syncytial virus infection with suspected bacterial secondary infection. The empirical therapy with macrolides was judged inappropriate in three of six cases mainly because of missing evidence for bacterial infection.

In conclusion, the rather low rate of inadequate prescriptions in this study compared to other studies suggests that continuous education of medical staff towards judicious use of antibiotics and the availability of inhouse guidelines may substantially contribute to the improvement of prescription patterns of antibiotics. Nevertheless, the inappropriate prescription of antibiotics in up to one of five cases demands that efforts be intensified to ensure continuous education of the medical staff. Their knowledge of and compliance with existing guidelines should also be expanded and updated at regular intervals. Finally, availability of novel or improved accurate rapid diagnostic methods to discern viral from bacterial infections may help reduce the high proportion of empirical therapy used in children because of their potential vulnerability to rapidly evolving bacterial infections in favor of pathogen-targeted therapeutic treatment.

\section{References}

1. John JF, Jr., Fishman NO: Programmatic role of the infectious diseases physician in controlling antimicrobial costs in the hospital. Clin Infect Dis 1997; 24: 471-485.

2. Coleman RW, Rodondi LC, Kaubisch S, Granzella NB, O'Hanley PD: Cost-effectiveness of prospective and continuous parenteral antibiotic control: experience at the Palo Alto Veterans Affairs Medical Center from 1987 to 1989. Am J Med 1991; 90: 439-444.

3. Schollenberg E, Albritton WL: Antibiotic misuse in a pediatric teaching hospital. Can Med Assoc J 1980; 122: 49-52.

4. Naqvi SH, Dunkle LM, Timmerman KJ, Reichley RM, Stanley DL, O'Connor D: Antibiotic usage in a pediatric medical center. JAMA 1979; 242: 1981-1984.

5. Townsend TR, Shapiro M, Rosner B, Kass EH: Use of antimicrobial drugs in general hospitals: IV. Infants and children. Pediatrics 1979; 64: 573-578. 
6. Kjellman B, Henningsson R: Patterns of antimicrobial therapy for pediatric patients. Scand J Infect Dis 1984; 16: 103-109.

7. Moreland TA, Rylance GW, Christopher LJ, Stevenson IH: Patterns of drug prescribing for children in hospital. Eur J Clin Pharmacol 1978; 14: 39-46.

8. Fosarelli P, Wilson $M$, DeAngelis C: Prescription medications in infancy and early childhood. Am J Dis Child 1987; 141: 772-775.

9. Kennedy DL, Forbes MB: Drug therapy for ambulatory pediatric patients in 1979. Pediatrics 1982; 70: 26-29.

10. Principi N, Marchisio P, Sher D, et al.: Control of antibiotic therapy in paediatric patients. II. Appropriateness of antibiotic choice in selected diseases. Eur J Clin Pharmacol 1981; 20: 119-121.

11. Lee KR, Leggiadro RJ, Burch KJ: Drug use evaluation of antibiotics in a pediatric teaching hospital. Infect Control Hosp Epidemiol 1994; 15: 710-712.

12. Mora $Y$, Avila-Aguero ML, Umana MA, Jimenez AL, Paris MM, Faingezicht I: Epidemiological observations of the judicious use of antibiotics in a pediatric teaching hospital. Int J Infect Dis 2002; 6: 74-77.

13. Marr JJ, Moffet HL, Kunin CM: Guidelines for improving the use of antimicrobial agents in hospitals: a statement by the Infectious Diseases Society of America. J Infect Dis 1988; 157: 869-876.

14. Shlaes DM, Gerding DN, John JF, Jr., et al.: Society for Healthcare Epidemiology of America and Infectious Diseases Society of America Joint Committee on the Prevention of Antimicrobial Resistance: guidelines for the prevention of antimicrobial resistance in hospitals. Clin Infect Dis 1997; 25: 584-599.

15. Divanon F, Hazera P, el Baroudi NE, Rennes C, Tanquerel JJ, Beck P: [Economic impact of rationalized antibiotic therapy in a general hospital]. Rev Med Interne 2001; 22: 737-744.

16. Thamlikitkul V, Danchaivijitr S, Kongpattanakul S, Ckokloikaew S: Impact of an educational program on antibiotic use in a tertiary care hospital in a developing country. J Clin Epidemiol 1998; 51: 773-778.

17. Gross R, Morgan AS, Kinky DE, Weiner M, Gibson GA, Fishman NO: Impact of a hospital-based antimicrobial management program on clinical and economic outcomes. Clin Infect Dis 2001; 33: 289-295.

18. Berild D, Ringertz SH, Lelek M, Fosse B: Antibiotic guidelines lead to reductions in the use and cost of antibiotics in a university hospital. Scand J Infect Dis 2001; 33: 63-67.

19. Blanc P, Von Elm BE, Geissler A, Granier I, Boussuges A, Durand Gasselin J: Economic impact of a rational use of antibiotics in intensive care. Intensive Care Med 1999; 25: 1407-1412.

20. Gyssens IC, Blok WL, van den Broek PJ, Hekster YA, van der Meer JW: Implementation of an educational program and an antibiotic order form to optimize quality of antimicrobial drug use in a department of internal medicine. Eur J Clin Microbiol Infect Dis 1997; 16: 904-912.

21. Vlahovic-Palcevski V, Morovic M, Palcevski G: Antibiotic utilization at the university hospital after introducing an antibiotic policy. Eur J Clin Pharmacol 2000; 56: 97-101.

22. Pestotnik SL, Classen DC, Evans RS, Burke JP: Implementing antibiotic practice guidelines through computer-assisted decision support: clinical and financial outcomes. Ann Intern Med 1996; 124: 884-890.

23. Durbin WA, Jr., Lapidas B, Goldmann DA: Improved antibiotic usage following introduction of a novel prescription system. JAMA 1981; 246: 1796-1800.

24. Lemmen SW, Becker G, Frank U, Daschner FD: Influence of an infectious disease consulting service on quality and costs of antibiotic prescriptions in a university hospital. Scand J Infect Dis 2001; 33: 219-221.

25. Saez-Llorens X, Castrejon de Wong MM, Castano E, De Suman O, De Moros D, De Atencio I: Impact of an antibiotic restriction policy on hospital expenditures and bacterial susceptibilities: a lesson from a pediatric institution in a developing country. Pediatr Infect Dis J 2000; 19: 200-206.

26. AAP. Red Bood 2000. Report of the Committe on Infectious Diseases: In: Pickering L, (ed): Elk Grove Village, IL: American Academy of Pediatrics, 2000.

27. Long S, Pickering L, Prober C: Principles and practice of pediatric infectious diseases. Churchill Livingstone, New York 1997.

28. Nelson J, Bradley J: Nelson's pocket book of pediatric antimicrobial therapy 2000-2001. Lipincott Williams \& Wilkins, Philadelphia 2000.

29. Kunin CM, Tupasi T, Craig WA: Use of antibiotics. A brief exposition of the problem and some tentative solutions. Ann Intern Med 1973; 79: 555-56o.

30. Swindell PJ, Reeves DS, Bullock DW, Davies AJ, Spence CE: Audits of antibiotic prescribing in a Bristol hospital. BMJ (Clin Res Ed) 1983; 286: 118-122.

31. Moss F, McNicol MW, McSwiggan DA, Miller DL: Survey of antibiotic prescribing in a district general hospital. I. Pattern of use. Lancet 1981; 2: 349-352.

32. Fischer JE, Ramser M, Fanconi S: Use of antibiotics in pediatric intensive care and potential savings. Intensive Care Med 2000; 26: 959-966.

33. van Houten MA, Luinge K, Laseur M, Kimpen JL: Antibiotic utilisation for hospitalised paediatric patients. Int J Antimicrob Agents 1998; 10: 161-164.

34. Kolar JV, Kadakova E: Prescription of antimicrobial drugs to hospitalized children. Ann Pharmacother 1993; 27: 974-977.

35. Tunger O, Dinc G, Ozbakkaloglu B, Atman UC, Algun U: Evaluation of rational antibiotic use. Int J Antimicrob Agents 2000; 15: 131-135. 